\title{
MIXED-MODE CRACK PROPAGATION IN FUNCTIONALLY GRADED MATERIALS
}

\author{
Jeong-Ho Kim ${ }^{1}$ and Glaucio H. Paulino ${ }^{2}$ \\ ${ }^{1}$ Department of Civil and Environmental Engineering, University of Connecticut, Storrs, CT 06269, USA \\ ${ }^{2}$ Department of Civil and Environmental Engineering University of Illinois, Urbana, IL 61801, USA
}

\begin{abstract}
Increasing performance demand in a variety of applications of functionally graded materials makes the fracture behavior of such materials very important for assessing and enhancing the structural integrity. This paper briefly reviews previous works on FGMs and mainly focuses on mixed-mode crack growth in FGMs. In this paper, automatic simulation of crack propagation in functionally graded materials is performed by means of a remeshing algorithm in conjunction with the finite element method. The crack propagation is performed under mixed-mode loading. Each step of crack growth simulation consists of the calculation of the mixed-mode stress intensity factors by means of a novel formulation, so-called non-equilibrium formulation, of the interaction integral method, determination of the crack growth direction based on a specific fracture criterion, and local automatic remeshing along the crack path. A specific fracture criterion is tailored for FGMs based on the assumption of local homogenization of asymptotic crack-tip fields in FGMs. The present approach uses a user-defined crack increment at the beginning of the simulation. Crack trajectories obtained by the present numerical simulation are compared with available experimental results. The present work provides a basis for further investigation on cracked FGMs under thermo-mechanical loadings.
\end{abstract}

\section{INTRODUCTION}

FGMs are multifunctional composites involving spatially varying volume fractions of constituent materials, thus providing a graded microstructure, macroproperties $[1,2,3]$. These materials were introduced to take advantage of ideal behavior of its material constituents. For instance, partially stabilized zirconia (PSZ) shows a high resistance to heat and corrosion, and CrNi alloy has high mechanical strength and toughness as illustrated in Figure 1 [4]. FGMs have been applied to the following applications: thermal barrier coatings [5]; first-wall composites in nuclear fusion and fast breeder reactors [6]; piezoelectric and thermoelectric devices [7]; graded refractive index materials [8]; thermionic converters [9]; dental and other implants [10,11]; fire retardant doors [12]; graded cathodes in solid oxide fuel cells (SOFCs) [13]; and other applications [2,3].

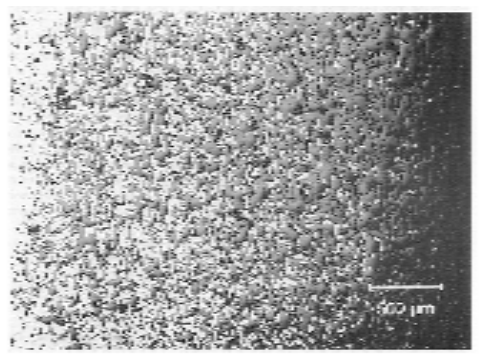

Figure 1 Micrograph illustrating graded transition region between $\mathrm{CrNi}$ alloy and partially stabilized zirconia (PSZ) [4].

Due to multifunctional capabilities, FGMs have been investigated for various damage and failure mechanisms under mechanical or thermal loads, and static, dynamic or fatigue loads, etc $[2,3]$. 


\section{SIMULATION OF CRACK PROPAGATION}

Automatic crack propagation in FGMs is performed by means of the I-FRANC2D (IllinoisFRANC2D) code [14]. The present code is based on FRANC2D (FRacture Analysis Code 2D) [15], which was originally developed at Cornell University. The extended capabilities of IFRANC2D consist of special graded elements to model nonhomogeneous materials, and fracture parameters for FGMs (such as SIFs) which are used to determine crack initiation and to predict crack initiation angles. Finite element simulation of automatic crack propagation involves successive steps. Figure 2 illustrates automatic crack propagation procedure at each step.

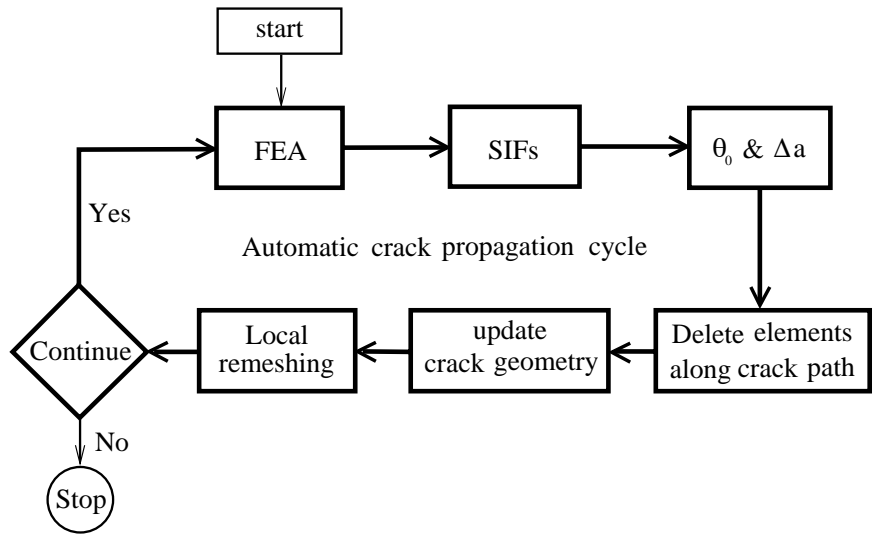

Figure 2 Automatic crack propagation procedure used in the I-FRANC2D code.

\section{THE INTERACTION INTEGRAL METHOD}

The interaction integral (M-integral) method is an accurate scheme to evaluate SIFs in FGMs $[16,17]$. We adopt a non-equilibrium formulation $[14,18]$, which uses displacement and strain fields developed for homogeneous materials, and employ the non-equilibrium stress fields $\sigma^{a u x}=\boldsymbol{C}(\boldsymbol{x}) \varepsilon^{a u x}$, where $\boldsymbol{C}(\boldsymbol{x})$ is the FGM stiffness tensor, $\boldsymbol{\sigma}^{a u x}$ is the auxiliary stress, and $\boldsymbol{\varepsilon}^{a u x}$ is the auxiliary strain. The interaction integral is derived from the path-independent $J$-integral [19] for two admissible states of a cracked elastic FGM body. The $M$-integral, based on the nonequilibrium formulation, is obtained as $[14,18]$

$$
M=\int_{A}\left(\sigma_{i j} u_{i, 1}^{a u x}+\sigma_{i j}^{a u x} u_{i, 1}-\sigma_{i k} \varepsilon_{i k}^{a u x} \delta_{1 j}\right) q_{, j} d A+\int_{A}\left(\underline{\sigma_{i j, j}^{a u x} u_{i, 1}}-C_{i j k l, 1} \varepsilon_{k l} \varepsilon_{i j}^{a u x}\right) q d A,
$$

where the underlined term is a non-equilibrium term, which appears due to non-equilibrium of the auxiliary stress fields, and must be considered to obtain converged solutions.

The relationship between M-integral and $\operatorname{SIFs}\left(K_{I}, K_{I I}\right)$ is given by

$$
M=2\left(K_{I} K_{I}^{a u x}+K_{I I} K_{I I}^{a u x}\right) / E_{t i p}^{*},
$$

where $E_{t i p}^{*}=E_{t i p}$ for plane stress and $E_{t i p}^{*}=E_{t i p} /\left(1-v^{2}\right)$ for plane strain. The mode $I$ and mode $I I$ SIFs are decoupled and are evaluated as follows:

$$
\begin{array}{ll}
K_{I}=M^{(1)} E_{t i p}^{*} / 2, & \left(K_{I}^{a u x}=1.0, K_{I I}^{a u x}=0.0\right) \\
K_{I I}=M^{(2)} E_{t i p}^{*} / 2, & \left(K_{I}^{a u x}=0.0, K_{I I}^{a u x}=1.0\right)
\end{array}
$$

The relationships of eqn (3) are the same as those for homogeneous materials [20] except that, for FGMs, the material properties are evaluated at the crack-tip location [21]. 


\section{A FRACTURE CRITERION}

The singularity $\left(\mathrm{r}^{-1 / 2}\right)$ and angular functions of asymptotic stress fields for FGMs are the same as for homogeneous materials [21]. This local homogenization allows the use of fracture criteria originally developed for homogeneous materials. Here we adopt the maximum energy release rates criterion proposed by Hussain et al. [22]. The energy release rate is given by [22]

$$
G(\theta)=\frac{4}{E_{\text {tip }}^{*}}\left(\frac{1}{3+\cos ^{2} \theta}\right)^{2}\left(\frac{1-\pi / \theta}{1+\pi / \theta}\right)^{\theta / \pi}\left[\left(1+3 \cos ^{2} \theta\right) K_{I}^{2}+8 \sin \theta \cos \theta K_{I} K_{I I}+\left(9-5 \cos ^{2} \theta\right) K_{I I}^{2}\right] .
$$

Then the crack initiation angle $\theta_{0}$ is obtained from [22]

$$
\partial G(\theta) / \partial \theta=0, \partial^{2} G(\theta) / \partial \theta^{2}<0 \Rightarrow \theta=\theta_{0} .
$$

The crack initiation condition is given by

$$
G\left(\theta_{0}\right)=G_{c}(\boldsymbol{x}),
$$

where $G_{c}(\boldsymbol{x})$ is the critical energy release rate function given by

$$
G_{c}=K_{I c}^{2}(\boldsymbol{x}) / E_{t i p}^{*} \text {. }
$$

\section{EXAMPLE: CRACK GROWTH IN AN EPOXY/GLASS FGM BEAM}

Rousseau and Tippur [23] investigated crack growth behavior of a crack normal to the material gradient in an epoxy/glass (50 vol\%) FGM beam subjected to four-point bending. Figure 4 shows specimen geometry and boundary conditions (BCs) of the FGM beam with a crack located at $\xi=0.37$. Table 1 shows the numerical values of material properties at interior points in the graded region. Material properties in the intermediate regions vary linearly.

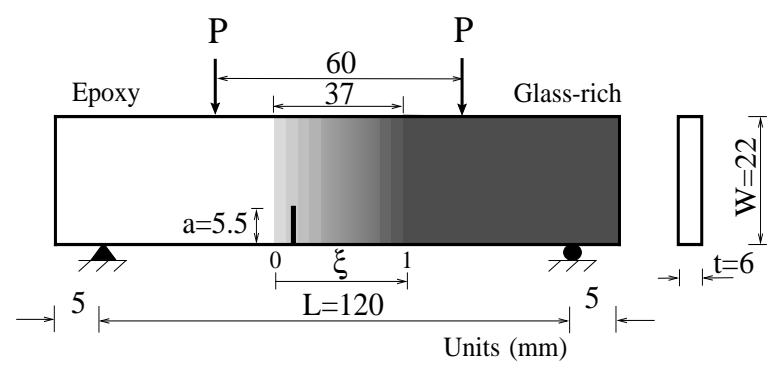

Figure 4: Geometry and BCs of the epoxy/glass FGM beam

Table 1: Material properties (Young's modulus $(E)$, Poisson's ratio $(v)$ and fracture toughness $\left.\left(K_{I c}\right)\right)$ at interior points in the graded region.

\begin{tabular}{|c|c|c|c|}
\hline$\xi$ & $\mathrm{E}(\mathrm{MPa})$ & $v$ & $K_{I c}\left(\mathrm{MPam}^{1 / 2}\right)$ \\
\hline 0.00 & 3000 & 0.35 & 1.2 \\
0.17 & 3300 & 0.34 & 2.1 \\
0.33 & 5300 & 0.33 & 2.7 \\
0.58 & 7300 & 0.31 & 2.7 \\
0.83 & 8300 & 0.30 & 2.6 \\
1.00 & 8600 & 0.29 & 2.6 \\
\hline
\end{tabular}


The following data are used for the FEM analyses: plane stress, $a / W=0.25, t=6 \mathrm{~mm}$, $P=P_{c r}(a+n \Delta a, \boldsymbol{X})$, where $n$ refers to the number of crack propagation increments, $\Delta a$ denotes a crack increment, and $\boldsymbol{X}=\left(X_{1}, X_{2}\right)$ denotes crack locations. Figure 5(a) compares experimental results for crack trajectory with those of numerical simulation $(\Delta \mathrm{a}=1 \mathrm{~mm})$. There is good agreement between two results. Moreover, experimental and numerical results for the crack initiation angle at the initial step are in good agreement, i.e. $\theta_{\exp }=7^{\circ}$ and $\theta_{\text {num }}=6.98^{\circ}$, respectively. Figures 5(b) and 5(c) show finite element discretizations at the initial and final steps, respectively, of crack propagation considering $\Delta \mathrm{a}=1 \mathrm{~mm}$.

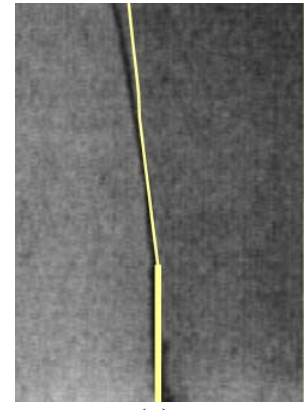

(a)

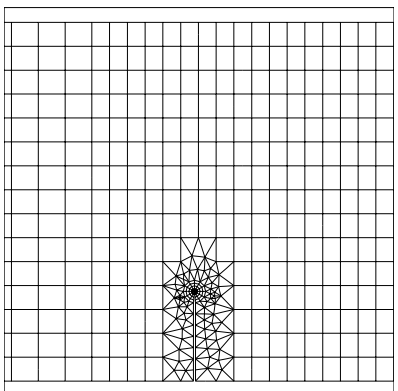

(b)

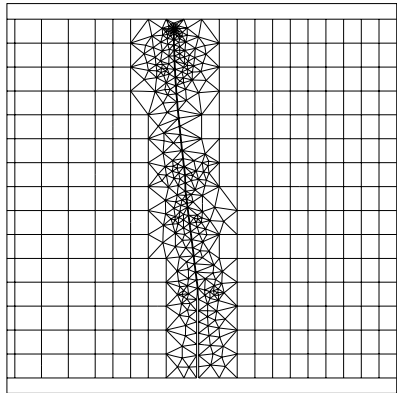

(c)

Figure 5 Experimental and numerical results: (a) Comparison of crack trajectory in the region $0 \leq \mathrm{W} \leq 16.5 \mathrm{~mm}$; finite element discretizations at the (b) initial (step 0) and (c) final step (step 16) of crack propagation [24].

\section{CONCLUSIONS}

This paper investigates fracture behavior of FGMs under mechanical loading by performing automatic simulation of crack propagation by means of a remeshing scheme in conjunction with the finite element method. Based on local homogenization, we use the maximum energy release rate criterion. Crack trajectories obtained by this fracture criterion agree well with available experimental results for homogeneous and FGMs. The computational scheme developed here serves as a guideline for fracture experiments on FGM specimens (e.g. initiation toughness and Rcurve).

\section{ACKNOWLEDGMENTS}

We gratefully acknowledge the support from the NASA Ames Research Center, NAG 2-1424 (Chief Engineer, Dr. Tina Panontin), and the National Science Foundation (NSF) under grant CMS-0115954 (Mechanics and Materials Program).

\section{REFERENCES}

[1] Hirai T. Functionally gradient materials and nanocomposites. In Holt JB, Koizumi M, Hirai T, and Munir ZA, editors, Proceedings of the Second International Symposium on Functionally Gradient Materials, volume 34 of Ceramic Transactions, pages 11-20, Westerville, Ohio, 1993. The American Ceramic Society. 
[2] Suresh S and Mortensen AQ. Fundamentals of Functionally Graded Materials. IOM Communications Ltd, London, 1998.

[3] Paulino GH, Jin $\mathrm{ZH}$, and Dodds RH Jr. Failure of functionally graded materials. In Karihaloo B and Knauss WG, editors, Comprehensive Structural Integrity, volume 2, Chapter 13. Elsevier Science, 2003.

[4] Ilschner B. Processing-microstructure-property relationships in graded materials. Journal of the Mechanics and Physics of Solids, 44(5):647--656.

[5] Hirano T, Teraki J, and Yamada T. On the design of functionally gradient materials. In Yamanouochi M, Koizumi M, Hirai T, and Shiota I, editors, Proceedings of the First International Symposium on Functionally Gradient Materials, pages 5-10, Sendai, Japan, 1990.

[6] Igari T, Notomi A, Tsunoda H, Hida K, Kotoh T, and Kunishima S. Material properties of functionally gradient material for fast breeder reactor. In Yamanouochi M, Koizumi M, Hirai $\mathrm{T}$, and Shiota I, editors, Proceedings of the First International Symposium on Functionally Gradient Materials, pages 209-214, Sendai, Japan, 1990.

[7] Tani $\mathrm{J}$ and Liu GR. Surface waves in functionally gradient piezoelectric plates. JSME International Journal Series A (Mechanics and Material Engineering), 36:152-155, 1993.

[8] Koike Y. Graded-index and single mode polymer optical fibers. In Chiang LY, Garito AG, and Sandman DJ, editors, Electrical, Optical, and Magnetic Properties of Organic Solid State Materials, volume 247, page 817, Materials Research Society Proceedings, Pittsburgh, PA, 1992.

[9] Desplat JL. Recent development on oxigenated thermionic energy converter - Overview. In Proceedings of the Fourth International Symposium on Functionally Gradient Materials, Tsukuba City, Japan, 1996.

[10] Watari F, Yokoyama A, Saso F, Uo M, Ohkawa S, and Kawasaki T. EPMA elemental mapping of functionally graded dental implant in biocompatibility test. In Proceedings of the Fourth International Symposium on Functionally Gradient Materials, Tsukuba City, Japan, 1996.

[11] Oonishi H, Noda T, Ito S, Kohda A, Yamamoto H, and Tsuji E. Effect of hydroxyapatite coating on bone growth into porous titanium alloy implants under loaded conditions. Journal of Applied Biomaterials, 5(1):23-27, 1994.

[12] Getto H and Ishihara SJ. Development of the fire retardant door with functional gradient wood. In Proceedings of the Fourth International Symposium on Functionally Gradient Materials, Tsukuba City, Japan, 1996. 
[13] Hart NT, Brandon NP, Day MJ, and Shemilt JE. Functionally graded cathodes for solid oxide fuel cells. Journal of Materials Science, 36:1077-1085, 2001.

[14] Kim JH. Mixed-mode crack propagation in functionally graded materials. Ph.D. Thesis, University of Illinois at Urbana-Champaign, Illinois, 2003.

[15] Wawrzynek PA. Interactive finite element analysis of fracture processes: An integrated approach. M.S. Thesis, Cornell University, 1987.

[16] Dolbow J and Gosz M. On the computation of mixed-mode stress intensity factors in functionally graded materials. International Journal of Solids and Structures, 39(9):25572574, 2002.

[17] Kim JH and Paulino GH. T-stress, mixed-mode stress intensity factors, and crack initiation angles in functionally graded materials: A unified approach using the interaction integral method. Computer Methods in Applied Mechanics and Engineering, 192(11-12): 1463-1494, 2003.

[18] Paulino GH and Kim JH. A new approach to compute T-stress in functionally graded materials by means of the interaction integral method. Engineering Fracture Mechanics, 71 (13-14):1907-1950, 2004.

[19] Rice JR. A path-independent integral and the approximate analysis of strain concentration by notches and cracks. ASME Journal of Applied Mechanics, 35(2):379-386, 1968.

[20] Yau JF, Wang SS, and Corten HT. A mixed-mode crack analysis of isotropic solids using conservation laws of elasticity. ASME Journal of Applied Mechanics, 47(2):335-341, 1980.

[21] Eischen JW. Fracture of non-homogeneous materials. International Journal of Fracture, 34(1):3-22, 1987.

[22] Hussain MA, Pu SL, and Underwood J. Strain energy release rate for a crack under combined mode I and mode II. In Paris PC and Irwin GR, editors, Fracture Analysis, ASTM STP 560, pages 2-28, Philadelphia, PA, 1993. American Society for Testing and Materials.

[23] Rousseau CE and Tippur HV. Compositionally graded materials with cracks normal to the elastic gradient. Acta Materialia, 48(16):4021-4033, 2000.

[24] Kim JH and Paulino GH. Simulation of crack propagation in functionally graded materials under mixed-mode and non-proportional loading," International Journal of Mechanics and Materials in Design (in press). 